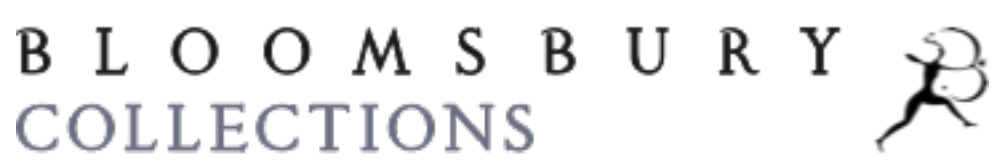

Nelson, Jason. "Poetic Playlands: Poetry, Interface, and Video Game Engines." Electronic Literature as Digital Humanities: Contexts, Forms, \& Practices. By James O'Sullivan. New York,: Bloomsbury Academic, 2021. 335-350. Bloomsbury Collections. Web. 26 Apr. 2023. <http:// dx.doi.org/10.5040/9781501363474.ch-030>.

Downloaded from Bloomsbury Collections, www.bloomsburycollections.com, 26 April 2023, 09:23 UTC.

Copyright (C) Volume Editor's Part of the Work ( Dene Grigar and James O'Sullivan and Each chapter (C) of Contributors 2021. Released under a CC BY-NC-ND licence (https:// creativecommons.org/licenses/by-nc-nd/3.0/). You may share this work for non-commercial purposes only, provided you give attribution to the copyright holder and the publisher, and provide a link to the Creative Commons licence. 


\title{
30
}

\section{Poetic Playlands: Poetry, Interface, and Video Game Engines}

\author{
Jason Nelson
}

If my digital poems could be jealous, if these interfaces could feel envy, a knee whacking desire to beat the competition, they would join together and gang-stomp the game engines. Out of the millions of users/readers my work has attracted, the poetry games dominate, drawing easily 75 percent of the interest (an emotive percentage). game, game, game and again game; $i$ made this. you play this. we are enemies; and Nothing You Have Done Deserves Such Praise have gone pseudo-viral on the web, with articles in national newspapers, magazines, blogs, Russian MTV, Brazilian televangelists, and other odd venues around the globe. More importantly these works spread through person-to-person, forum-to-forum, message-to-message, post-topost, meme-to-um ... -meme-maker, creating a personal sense of discovery and reader-ownership driving viral processes.

Why are the digital poetry/art games so much more compelling, more attractive, more interesting, more magnetic to a wider audience than my (or any other's) work? Some might point toward the near-crazy hand-drawn sketches and mix of strange video tales and universal themes. But many of my works are equally as baffling and paranoia-inducing, just as strange and sensational, unlocked monsters, tendrils from the subconscious. Instead, I hypothesize/guess/vaguely stab it is the game interface that sparks the work's popularity. The game interface, and certainly the platform- (Mario Brothers) style engine I use, is instantly familiar and engaging to anyone who 


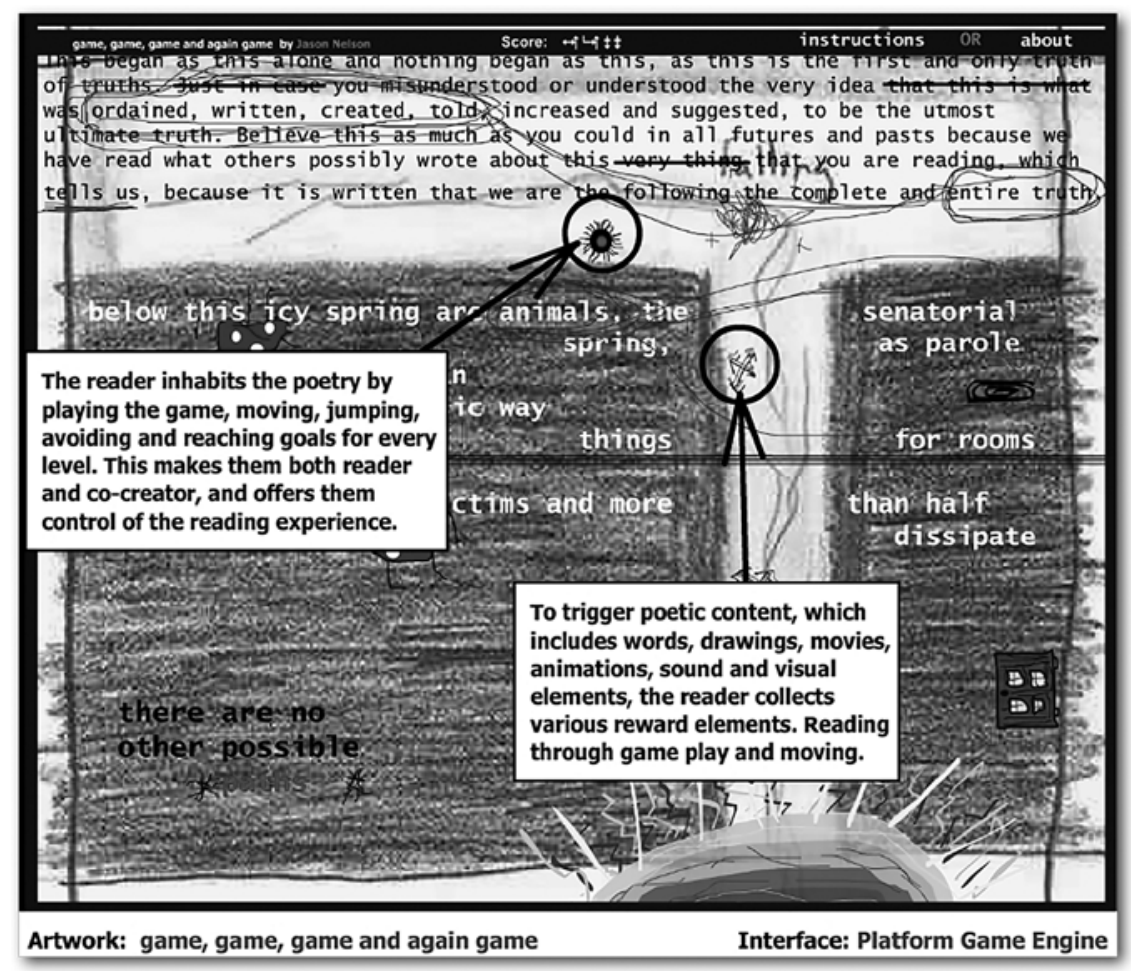

FIGURE 1 game, game, game and again game.

has grown up after the 1970s. Despite the immense advances in computer power and possibilities, the platform game continues to occupy a dominant and heart-spun space on the virtual gaming shelves.

This familiarity operates as a foothold, a climbing rope, a ladder, a doorway into what is otherwise a strange foreign world for most users/ readers. Relatively few people read poetry (compared to cereal boxes), let alone experience net or digital art outside of a school setting-and combining the two can let them inhabit the work, to live in the giant Gerbil cage, pressing left, right, up, and mistakenly down.

The platform game engine is a linear journey with non-linear side roads, lost cemeteries of the digital settlers/pilgrims. The user/reader/player begins the game/level (typically on the screen's left) and continues, following a pathway to reach a goal (and move on to the next level or win prizes, or fall forever through a coded error). And while the poet cannot determine the exact path each player/reader will take, you can be fairly certain they will trigger specific instances should they want to move forward. This strategy might seem obvious, but it does have considerable impact on how the digital poem is constructed. 
Video games are a language. They have created their own grammar, their own understanding based on rules, exploration, movement, and response. While I think certain segments or aspects of culture have been greatly impacted by video games, I don't feel that games have infiltrated fully into culture, certainly not when compared to other entertainment or communication or artwork forms. This is not to say that games cannot move beyond the same structures/game plays and ideologies that have dominated them for the last thirty years. However, there must be a greater effort made by both game makers/developers and the gaming audience to accept games on the same level as great artworks, works of literature, or music. Both groups need to learn how to "read the texts" of video gamesin a more literary way, to truly play with the grammar/culture and possible new formats for video games.

To add something about online gaming worlds: the power of online gaming could be immense. The occasional news story about parents neglecting their babies to play World of Warcraft are a testament to that power. However, I am continually surprised at how unimaginative most of these online worlds really are. Most of the basic features in terms of fantasy or strategy are well worn clichés, and the adherence to earth-like physics is sadly uncreative. Why aren't video game creators or players demanding truly innovative gaming worlds where truly anything is possible, instead of re-treading Dungeons and Dragons? Let us make worlds of creatures that without the technology could never have been imagined and then given a visual/interactive birth. Then video games just might advance the culture in unexpected ways.

But what do videogames and poetry have in common? As mentioned, video games are a language, a grammar or linguistics for various texts. The sounds, the movement, the graphics, the rules (or lack of rules)—everything about a video game is a component of some kind of language. While poetry is traditionally taught as being constrained to words, I think of poetry as being based on texts. I mean "texts" in the broadest sense: all the elements, media, code, and artefact within a digital poetry game become a literary element/tool/device.

Therefore, the video game format, even the basic platformer game or point and click interfaces, or 3-D flying spaces I've toyed and tinkered with, are perfect grounds for a poetic playland. Additionally, many digital poems are inherently born from non-linear thinking and writing. Indeed, if technology drives poetry games, equally traditional book/page formats constrain the poem to line by line, pressed letter by bound page. But interactive technologies, and especially the game format, offer the poet the chance to make their poems not only multi-dimensional, but also interactive and multi-temporal. Prior to building haphazard coding skills, I conceptualized my creative writing as a visual element translated into words or music, then reformed into print language. To have all these elements, combined with the 
added tools/texts of movement and interaction and dimensionality, frees up the poetry writing process in curious and wondrous ways, a meandering creek flooded free into the spidering valley.

The video game format has the additional benefit of acting as a foothold or a bridge for readers. Unfortunately, relative to other forms of communication and textual input/output, poetry readership hasn't kept pace. In my adopted homeland of Australia, a good-selling poetry book might sell a thousand copies. But my digital poetry, my games and strange interfaces, even the least popular and most difficult to understand attract tens of thousands of readers, and my most popular coax millions into playing.

The question then arises, from its long slumber half covered in shaved paper bedding, why does digital poetry appeal or at least invite so many readers? The most immediate reason is the game interface offers a familiar and inviting interface, a fun or at least interactive way for the reader to feel involved with the poetic space. The poet ceases to be an authority and instead becomes a combination of guide, artist, and theme park ride operator. Additionally, the diversity of texts within the digital poem creates, as they say in cliché-land, "something for everyone." Whereas some readers might love the combination of ambient soundtrack and responsive words, others might adore the interaction of explosions and literary allusions to religious laundromat pamphlets.

\section{game, game, game and again game}

game, game, game and again game is/was a digital poem, retro-game, an anti-design statement and a personal exploration of the artist's changing worldview lens. Much of the Western world's cultural surroundings, belief systems, and design-scapes create the built illusion of clean lines and definitive choice, cold narrow pathways of five colours, three body sizes and encapsulated philosophy. Within net/new media art the techno-filter extends these straight lines into exacting geometries and smooth bit rates, the personal as WYSIWYG (What You See Is What You Get) buttons. This game/artwork, while forever attached to these belief/design systems, attempts to re-introduce the hand-drawn, the messy and illogical, the human and personal creation into the digital via a retro-game style interface. Hovering above and attached to the poorly drawn aesthetic is a personal examination of how we/I continually switch and un-switch our dominant belief systems. Moving from levels themed for faith or real estate, for chemistry or capitalism, the user triggers corrected poetry, jittering creatures, and death and deathless noises. In addition, each level contains short videos from the artist's childhood, representing those brief young interactions that spark out eventual beliefs. game, game, game and again game is less a game about 
scoring and skill and more an awkward and disjointed atmospheric, the self-built, jumping, rolling meander of life.

Software, such as Adobe Flash or Photoshop, used to dominate the appearance and feel of images and artwork. This was partially due to the software's data processing methods (Flash loves vector, heart emoticon) and the limited range of tools and filters. The mouse also constrains the artist's ability to escape the software's overpowering aesthetic and, thus, removes or at least submerges much of the individual from many digital images. But in gggag I strove for a sense of anti-design within the design by relying on the hand-drawn.

Therefore this game/artwork began on paper, with charcoal and coloured pencils, each level born from the immediacy and error/curve/(e)motion of electricity-less drawing. This hand-drawn approach breaks the artwork away from both the oppressive control of software and much of design culture. In essence, this artwork/game was created as if the audience consisted of only the internal self, an offering of the personal with all its incongruities and confusions and small beauties.

Technology can be used to remove the errors and mistakes of human creation, with a prevalent emphasis on usability and glitch-free user operation. And while this artwork follows those conventions in function, it revels in the quirky, immediate corrections of the marked and corrected environment through the artwork/game. The poetic texts and animated drawings, triggered by the user/reader's movement are incomplete and in process of being edited and altered. Thus, the work itself becomes a notebook or sketchpad of personal ideas and insights into what falls away from "finished" creations.

Perhaps the most direct method of inviting the user/reader to invest the self into their experience is to offer them direct control of how the artwork is experienced. In this creation that user-inhabited space is contrasted with the creator's personal journey through belief systems. In the process of reading, the user might feel simultaneously enthralled and alienated, which mirrors the individual's experience with all group-think cultural constructs. In addition, the direct connection between action and content, between direction and poetics, encourages the user to rethink the images, drawings, and poetics in the light of the actions that opened that content.

Each of the levels within game, game and again game is themed/centered around a particular belief system. These systems do not inhabit religious grounds and, instead, emphasize the filters individuals use to interpret their surrounding culture-scape. The game play and poetics extend from these various belief systems. For example, within the Chemist level, which examines drugs as worldview, the syringes open surreal texts and rave-like graphics, and the game play path is largely illogical and deceiving. On the Faith level, the user has to choose between the two sides of the cross, with one choice offering a deathless death and the other continuing the path, 
with satirical and irreverent poetics inspired by personal events/encounters with Christianity.

Adding to the mix of personal artefact, journey, and art game are the family audio commentaries embedded into the level prize videos. These videos, shot in $8 \mathrm{~mm}$ by my grandfather (whose last word was "gizmo"), were digitally captured by a handheld camera with the audio coming from family commentaries about the events within the videos. These remembrances are directly related to the belief systems each level explores and extend the personal, intimate thoughts into the meta-poetics of the artwork/game.

As most games have constant soundtracks and sounds/noises that clearly identify with the action or object that triggers them, this artwork/game uses sound to disjoint and translate the experiences. All levels use a different loop exploring speed, cadence, and tone to play on emotional and physical responses and to contrast or compliment particular level themes. The effects I was seeking are described by Jan Baetens and Jan Van Looy:

From a cultural viewpoint, there are several reasons for justifying a strategic alliance between e-poetry and sound, but the strong embedding of e-poetry in the historical avant-garde is by far the most salient one. A second explanation for the text-sound link is a mechanism of psychological compensation. It is often argued that cyberculture virtualizes the body, and that this virtualization engenders different types of fear that need to be averted by an opposing mechanism of foregrounding the body.

(Baetens \& Van Looy 2008)

The game interface used in this artwork is more than twenty years old, dating back to early Mario Brothers and before. This familiar game play and interface was important in the creation of this artwork in that it provided an immediate and nearly invisible gameplay environment and allows the user/reader to immediately identify with the digital space. The poetry game becomes less about deciphering the conditions/rules of play and more about the contrast between the format and the poetic and drawn "content," intimate and personal, a direct extension of the artist's (my) ideologies and self.

With the gameplay being so familiar, the artwork recontextualizes some of the main features of the game. For example, the score, replaced with arrows/characters, continually spins, responsive to game play but numerically meaningless. There are unlimited lives available in the game, with the only negative consequence of encountering an enemy being pushed back to the level's starting point, accompanied by an announcement in a disembodied voice: "Come on and meet your maker" (now a slogan for a Danish fashion house). Some levels use the "warp" function to transport the creature to certain locations. This warping is taken to absurdity in the levels where the character cycles through falling, and represents the fruitless personal investigation of belief and the always altering lens. 
game, game, game and again game was born from the skeleton of a retro game engine and 13 hand-drawn levels. Instead of thinking about game play and level design, my approach was to draw personal impressions of belief systems on paper and to use those drawings to create the game play of each level.

\section{i made this. you play this. we are enemies}

$i$ made this. you play this. we are enemies is an art-game, interactive digital poem which uses game levels built on screen shots from influential community-based websites/portals. The game interface drives the poetic texts, the colliding and intersecting images, sounds, words, movements, a forever changing, reader-built poetic wonderland. Using messy hand-drawn elements, strange texts, sounds and multimedia layering, the artwork lets users play in the worlds hovering over and beneath what we browse, to exist outside/over their controlling constraints. Kiene Brillenburg-Wurth describes this layering as "together-art" and says it is "often an art of fusion: different media are not merely combined, but welded into a hybrid that rewrites older versions of the media involved" (Brillenburg-Wurth 2006: 6). In my case, the game engine and its myriad of media and interactive content is intended to create this fused artistic and poetic environment, with the arrow keys and space bar guiding you, and the occasional mouse click begging for attention. It is an ideal method of creating this collaged and layered effect, precisely because the game engine allows for triggered content to be the goal of the key/mouse-driven user/reader movement.

Each day the internet is humming with a million small interventions. From the humoresque mocking of community content sites like Fark, to the net gate-keepers Yahoo and Google, partisan political portals like Huffington Post or the open source/file sharing "pirates" of Mininova, the web is an easy tool/weapon for meddling/influencing and sharing/forcing/alluring your opinion on whomever clicks. Yet this digiscape is a deceiving and uneasy place, with continual streams of generic expression/content, cute dogs, and accident clips knocking against an incredible range of political/social beliefs hidden beneath the screen. Even short sequences of words, titled links, or blinking ads can reveal the strange, wondrous, and treacherous.

\section{Timely Insert: Reactions to My Series of Game-Engine Interface Poems}

An anonymous player of my newest art game Scrape Scraperteeth verbosely, and with great pixilated venom, described all the ways my game entirely and completely failed. Aside from poor playability, hobo-esque design, and 
crashing coding, he spent a considerable effort blasting me personally. Suggesting I was an art school wanker with serious mental health issues and most likely had a sordid criminal record filled with all manner of sexual deviances, he ended his diatribe with a direct threat to my skin and bones should I make another work. Others in the same forum quickly leaped to his side, wielding great textual swords of agreement. But, surprisingly, hidden in the bitter streams are islands of love, chiming comments of adoration. They tend to be quieter (as is the law of internet land), showing me love through back alley emailing or reviews and sharing my work on obscure and major sites across the net.

Since 2007, when I released game, game, game and again game into the gaming world (followed by six or seven more games depending on ludology), the above scenario of extreme hate or love from a polarized audience has played out many dozens of times, across all continents in a bizarrely broad range of web portals: from drug enthusiasts to adult content, in major international magazines and even elementary school syllabi. My games struck and continue striking nerves and brain stems, inspiring the sharing of something so odd, so terrible or compelling, citing notions about games that are not games, art that is not art, poetry that is, well, poetry.

In Oklahoma, where I was raised, belief systems dominate social life. For some it is Baptistic evangelism, others are ruled by Oklahoma Sooners football and everyone worships oil. So game, game, game and again game was built for a poetic exploration of such life-dominating notions as real estate, pharmaceuticals, or Buddhism. The hand-drawn backgrounds were created both from frustration with the ultra-clean/perfect design aesthetic of most net art and my yearnings to create a hand-made facade. One of the game's most baffling aspects are the home videos. In essence, these represent my belief system, as cheesy as it sounds, of family, with the first level's clip my mother coming out of the hospital with newly-born me in her lap.

Admittedly, a common comment about my work is simply "WTF?!" And I blunderstand why some post that critique/observation. I did not set out to share my work in popular internet forums, nor intend to play the role of "crazy dude" in gaming circles. game, game, game and again game and others were created as digital poems for the electronic literature community, built for galleries and academic venues. While the game was happily accepted by artists and professors, the notion of having an audience of only a few hundred (attending for free wine/cheese or because it is a university course requirement) was entirely unsatisfying. Around that time, I was helping a German PhD student (Jens Schroeder) with research into video games (involving crashing games conventions) and after a few beers where I complained about the tiny hit counts of art realms, Jens suggested I try sending my game-like creature to popular gaming blogs or culture portals. 
On his advice, I sent a poorly crafted email to the generic info/tips/ contact addresses of such sites as Kotaku, Joystiq, Destructoid, Jayisgames, and others. Previously, as a lark, I inserted a "send me an email" note on the game's final screen. Not being used to receiving messages from anyone other than complaining students or failed eBay bid notices, I left my email unchecked over the weekend. Then on Monday morning my usual four messages were replaced by a few hundred. Within my server statistics I found all the above game blogs (and numerous cleverly named others) had reviewed my work, and indeed the game continued spreading and spreading over the next weeks and months.

As an artist it was an awakening. Here was an artwork, considered experimental in the fields of electronic art and writing (a digital poem and art-game for crusty crunk's sake), and it was being discussed, shared, blasted and praised as a game. I wasn't prepared for the extremes of player's responses. There were creative and disturbingly specific death threats, marriage proposals, including images of shaved and unshaved areas circled and labelled with detailed directions. Some people sent money, and others gave suggestions for psychiatrists. Every morning the messages kept coming, and I became addicted to checking my server statistics and vainly searching for the latest exposure.

After game, game, game and again game's viral (a terrible cliché) spread tapered, I itched to make another art game. I spent months creating the zombie shooter-inspired Alarmingly these are not Lovesick Zombies. I explored a perpetual enemy shooter engine as a way to create an interactive sculpture generator. I crafted background videos for mini-narratives and toyed with the notions of absurd scoring goals and having levels reachable only upon losing. And sadly the game was a disaster. I had let the WWW attention camp in my head, and thus I created a game weird for the sake of being weird. Somehow the internet collective consciousness picks up on disingenuous creations and destroys them with the hammer of disinterest. If you are going to create an abstract hand-drawn poetry art-game, do it from your unique imagination (the back of your head) and not from what you think will disturb others or get the most hits. The game was met with relative web silence and sank like a narcoleptic cake-heavy synchronized swimmer. So, I decided to go back into my safe academic world and never make another game, ever, never, ever. Sniff. Sniff.

Thankfully, my gamer-hating, zombie-loving, emo-esque party lasted less than a month. What broke my brief funk was, oddly and appropriately enough, the webmaster of a series of "adult video" sites: almost a dozen sexytime clips, hot kitten, people humping websites listed gggag as a top link. As you might expect, the visitor count was massive, and with my work saving tons of lubricating jelly and paper towels, I was recharged. If my game could disrupt the hormone-fuelled drive of browsers, maybe my brand of artsycrazy-poetry-game still had legs, arms, and other intertwined body parts. 
I decided to thematically center my next art game on what had been preoccupying my mind for the previous year: the strange bipolar space of the gaming community and its love and hate of my craptastic creations. So in mid-2008 $i$ made this. you play this. we are enemies was born. The aptly-titled game used screenshots of popular web portals, from the lumbering beasts of Yahoo/Google to fancy-pants sites like BoingBoing and Metafilter, for the level designs. I wanted to create the effect of doodle annotation, of marking up the screenshots with commentaries about the portals and what they represented. The player becomes the doodler, with each coin-like reward adding to the visuals. Oddly, introducing the idea of an intermission seemed to spur incredible numbers of emails. These missives weren't so much commentary about the use of an intermission as they were the result of a pause in the frenetic insanity. I also attempted to introduce more traditional game elements, more enemies, harder level design, and secret transporters. An unpublished version of the game included five additional levels inspired by ESPN, Suicide Girls, and others. Their exclusion had more to do with keeping the game size manageable than content issues.

$i$ made this. you play this. we are enemies spread even more than game, game, game and again game, showing up in newspapers such as the New York Post and Der Speigel, on Russian MTV, and in magazines like Wired and others. This repeat success seemed to signal one thing: there were gamers hungry for the strange and unique, for the odd combination of poetry and art in a world dominated by clean graphics and complex game play. It even inspired some lovely copyright battles because deeper in the game are three appropriately sequenced levels utilizing Disney's main page, the RIAA (the folks that sued grandmotherly pirates) and Mininova (at the time a major BitTorrent destination). I received a few threatening emails from prestigious-sounding law firms demanding all sorts of madness. I would like to think my academically driven responses, hinged on satire laws, made them go away. Instead, it was most likely all those that stole the game's SWF (Shock Wave File) and placed it on gaming portals making their task seem impossible.

The follow-up, and one of my most literary theory-driven games, was Evidence of Everything Exploding. Continuing with the annotating doodle design approach, I chose cultural documents for the level designs, representing pivotal or interesting moments in recent human history: Bill Gate's Computer Brew letter (where he argues for charging for software), a government warning about the pre-World War I flu pandemic, the NASA moon landing document, and the patent for the pizza box among others. Moving away from the platform engine, I used a top-down shooter engine while including some of the same tricks as in previous games for popup narratives and other artistic content. Keeping with the theme of these documents as keys to our social puzzle, I included locked areas and required 


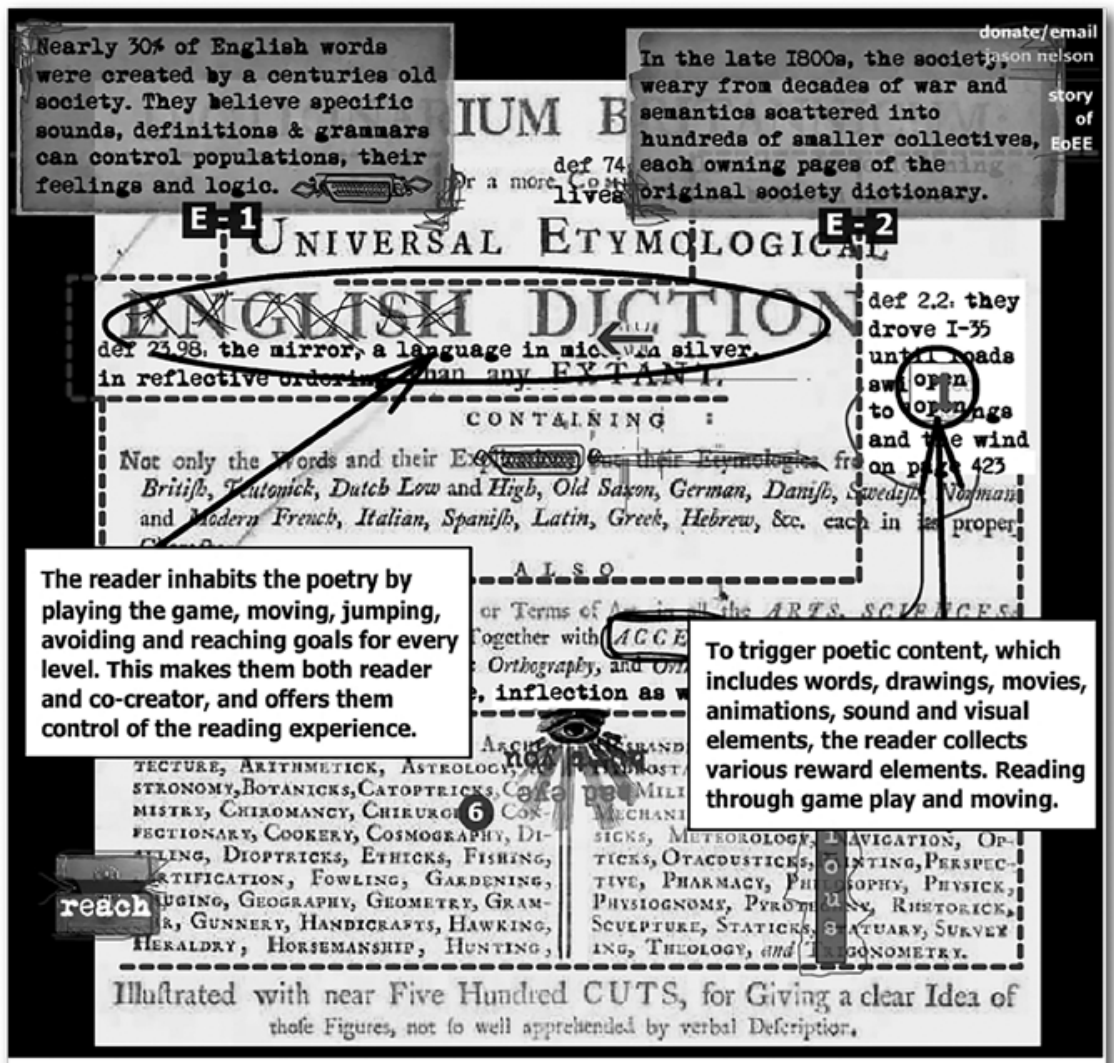

Artwork: Evidence of Everything Exploding Interface: Top-Down Game Engine

FIGURE 2 Evidence of Everything Exploding.

exploration for keys chased by more complex enemies. In some ways the increased difficulty of Evidence of Everything Exploding made for a smaller audience, as it hit that murky middle ground between proper game and art experience.

\section{Evidence of Everything Exploding}

Using documents, both historical and little-known from Bill Gates, NASA, James Joyce, Dadaism, Neil Gaiman, Fidel Castro, and others, the art game Evidence of Everything Exploding explores those strange moments where history does or does not turn, where unusual forces collide to create or 
topple storylines to build new futures. With the same hand-drawn, markedup style, this game uses a Maze engine to guide the player through unsolvable puzzles. On each level are prophecies and stories inspired by the history and events the documents represent. The madness of the pages meets the madness of the game. And as Astrid Ensslin so beautifully describes, the surreal nature of the work acts as both vehicle for poetic wonder and as a way to inhabit the reader, to fix them breakfast, drive them to work and rethink/reconstruct their surround-scape through a surrealist lens (Ensslin 2014: 225).

Using a top-down platform engine (without gravity) Evidence of Everything Exploding is a game-driven digital poem exploring various historical and contemporary texts. Each level's poetic content is built from the document's sub-sub texts and curious consequences. With Bill Gates's letter to the Computer Brew Club about monetizing hobby computing, we find the seeds of an empire; James Joyce is caught in an infinite loop of changing texts; Fidel Castro's boyhood letter to the US president praising America and asking for money signals an opportunistic future.

Since then, I've created a whole herd of other less gamey excursions into interactive poetry and dynamic/generative digital art. These works, while well regarded in some realms, never reached the same massive audience as those using a game engine. Games are a common interface, a universal language. They are a ladder and a foothold for the average player to experience abstract art/poetry. When driving in Mongolia you might not know what the signs say but you know enough about the shapes and directions to find your way to the hotel without smashing into overloaded delivery trucks. Like all other creative tools, games can be anything the creator imagines, toying with, or destroying entirely, player expectations and becoming poetry. Yet there are some who argue against this notion of a game becoming a poem. Joseph Tabbi argues the boundaries between digital art, computer games, and digital literature are blurred, yet those distinctions are necessary,

so that a literary language [can] create its own self-awareness, its own specificities, genres, and supporting networks that are needed to distinguish the literary arts from visual, oral, and computational media ... Where games demand interaction and where conceptual arts bring us to a new, embodied understanding of the primacy of perception in the arts, literature does something else, something requiring continuity and development, not constant interruption through the shifting of attention from one medium to another.

(Tabbi 2010: 39)

And while I agree literature does do something else, does demand attention, and continuity from the reader and writer, the two-the game and the 
poem-are not mutually exclusive. Additionally, the shifting attention is exactly the poetic point in many of my works: I intentionally adjust between form and media and meaning within the game environment.

\section{Scrape Scraperteeth}

My latest art game Scrape Scraperteeth, commissioned by the San Francisco Gallery of Modern Art, was built from the directive to make a small-scale creation, simple, and representative of my previous works. While it is not an entirely new take on the digital poetry game form, it does uniquely focus on one of the dominant events of the past few years: the real estate speculation crash. I love the notion of creating micro-games as artistic/poetic commentary on important news events or controversial topics. It might not be a complicated game but as an artistic statement I am charmed by its singular focus. Unlike many of my previous works, its primary thematic focus is a political message. Thus, it does showcase the varied usages of a game interface for digital poetry and how the platform engine can be an ideal canvas for a variety of possible poems.

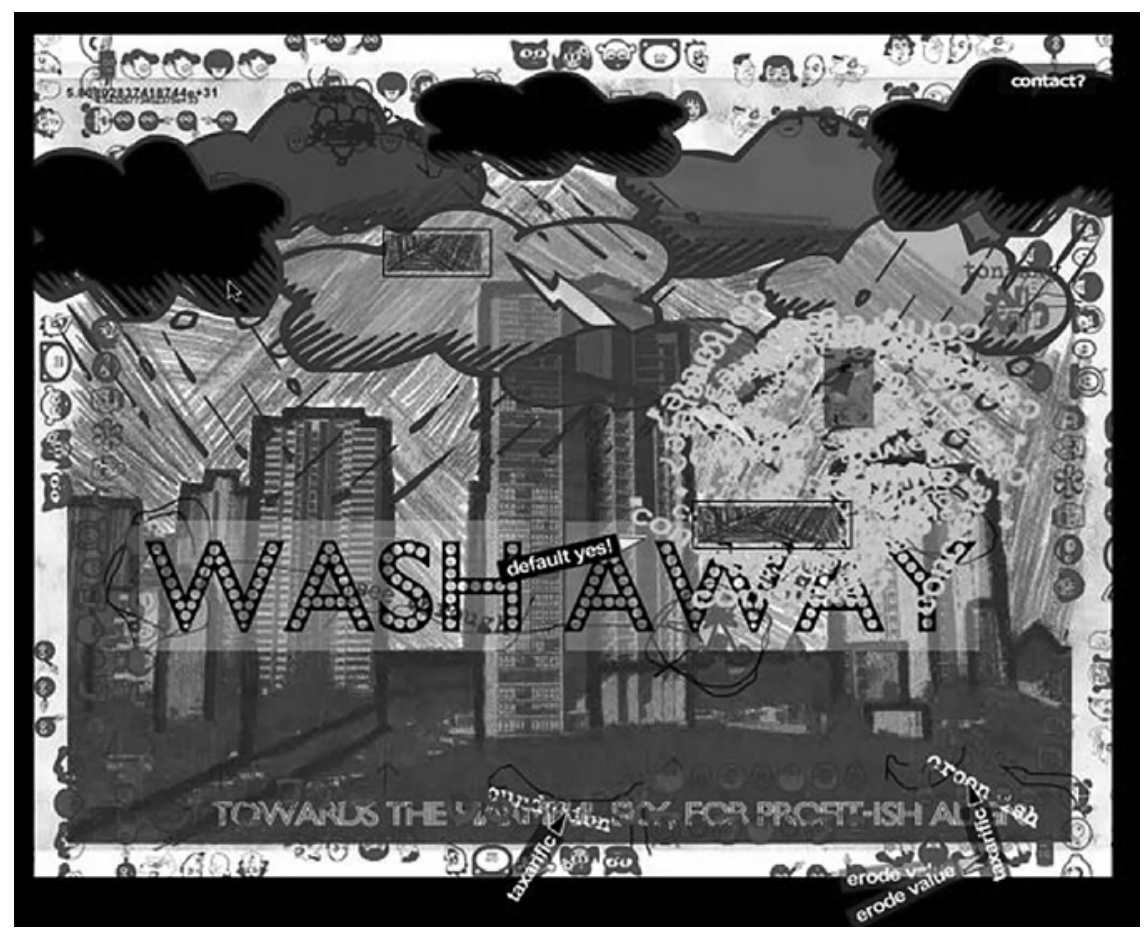

FIGURE 3 Level One: the stormy cityscape of Scrape Scraperteeth 
Scrape Scraperteeth also represents the movement of an interface from experimental form to an established approach to building digital poems. As such, I could explore other facets of the game environment previously unexplored. For example, I included textual elements that follow the hero/ creature, creating a dynamic poetic layer for each layer. Additionally, the explosions for each reward use text as a visual element, creating animated concrete poems each time they are triggered. I am particularly charmed by the hand-drawn backgrounds, which, unlike my previous games, utilize and examine geography and location via photographs of the Gold Coast (Australia) skyline.

In no way does detailing my game-making experiences intend to say "look what a great artist I am" or "I'm more popular than Kangaroo Jack" (I've always wanted to type that). Indeed, I admit I am not a great game maker. My drawings are messy, and my work is difficult for those outside the net-art/digital poetry spheres to understand. Instead, my intention is to show how creating games that are truly unique with a reckless abandonand without regard to convention can actually lead to interesting artwork and also to a substantial audience. Yes, half your audience might hate you with words of violence and bitterness, but the other half will send you long, adoring notes of how your work reached some unused part of their brain, a brief crazy escape from the madness of their daily life.

\section{The Flash Wake and The Forced Pet Metaphor}

Autopsies are sometimes inconclusive, certainly when the dead remain breathing, life support pushing code into a shallow chest. Breathe, stope, breathe, stope. All extra Es.

But I've, we've, known Adobe Flash was dead/dying for at least three to four pet gerbils (depending on care and concern). So, when we arrive, collectively, at the cage one morning and our wee furry prisoner will not respond to high pitched calls or whiffs of cheese, and we ponder irrational revival methods (microwave, mouth-to gerbil mouth, surprise birthday party), the rodent's demise should not be unexpected nor feared. Gerbil maladies are rarely contagious to Javascript. Rarely.

The dominance of Flash during that time period is an important signifier for the aesthetics of Internet culture at the time. Its ability to mix text, animation, rough video, sound, and a wide range of interactive elements within the one browser window drove the look of many works of e-lit at the time, as well as the wider Internet of the produser.

(Krauth 2018: 257) 
Inevitably, we ponder new creatures to "own," to reinforce our control over the immediate-scape. What makes this process so difficult is how addicted many of us were to the interface, the interaction, the multi-modal, multi-layered nature of Gerbils? Dogs, cats, miniature stretch-bears are all glorious creatures with which to play and engage. But they are unwieldy, difficult to train, and easy to un-train. Building digital poetry games from the bark of dogs sometimes makes for dramatic, yet hollow, trees, all crust and tower, crashing into power lines during even soft rains.

Since Scrape-Scraperteeth (my third best title), I've adventured into the long and high-grassed fields of heavy code or engines designed for the propelling of games and re-frozen foods. Prepare, cook, package, ship, leave on the street while dealing with the dangerous twin-terrors of needles and pie fillings, defrost, re-freeze. A creative process, $\mathrm{I}(\mathrm{T})$ says being semiacademic with a horror movie identity.

My future games are no longer organic pets built in the warm belly of Flash. They are erratic and stumble-drunk monsters with cybernetic limbs and processors for brains. As clumsy machines they are near immortal, alive, and scratching until the societal skill of forcing electrics through wires collapses in the maddening choice to canonize a real estate scam artist. Titles, the soft dough of a poet. Games, the risen disk, piled with the arbitrary remains of pets and practitioners. The same disease that ends an interface is the same disease that ends what's hiding in the cage.

\section{References}

Baetens, J. \& Van Looy, J. (2008), "E-Poetry Between Image and Performance: A Cultural Analysis”, E-Media studies, 1 (1). doi: 10.1349/PS1.1938-6060.A.288

Brillenburg-Wurth, K. (2006), “Multimediality, Intermediality, and Medially Complex Digital Poetry”, RiLUnE, (5): 1-18.

Ensslin, Astrid (2014), "Womping" the metazone of the Festival Dada: Jason Nelson's evidence of everything exploding. 221-231.

Krauth, A. (2018), "Electronic Literature”, Barney Warf (ed.) The SAGE Encyclopedia of the Internet, 257-258.

Nelson, Jason (2007), game, game, game and again game. Available online: http:// www.secrettechnology.com

Nelson, Jason (2008), i made this. you play this. we are enemies. Available online: http://www.secrettechnology.com

Nelson, Jason (2009), Alarmingly these are not Lovesick Zombies. Available online: http://www.secrettechnology.com

Nelson, Jason (2011), Evidence of Everything Exploding. Available online: http:// www.secrettechnology.com

Rettberg, Scott (2019), “Electronic Literature”, Wiley.

Tabbi, J. (2010), "Electronic literature as world literature; or, the universality of writing under constraint”, Poetics Today, 319 (1): 17-50. 
